\title{
One stage versus two stages strategies in the management of femoral shaft infected non union
}

\begin{abstract}
Background: Infected nonunion of femur is one of the most challenging complications, there are several treatment modalities as segment transfer and vascularized fibular graft but none of them was considered the gold standard as they are associated with complications including recurrence of infection and knee stiffness and complications of external fixation
\end{abstract}

Material: In our study we retrospectively reviewed thirty patients with femoral shaft infected non union.

Methods: patients were divided into two groups; sixteen patients were treated by single stage strategy and fourteen cases with two stage strategy.

Results: we compared between the two groups as regard: range of motion of nearby joints, time till full union, number of operations and associated complications.

Conclusion: Two stage strategies had better results as regard range of knee motion but higher risk of recurrence of infection.

Keywords: femoral non union, infection, external fixation, intramedullary nail
Volume I Issue 2 - 2017

\begin{abstract}
Khaled M Emara,' KhaledAbd EL Ghafar, ${ }^{2}$ Ramy Ahmed Diab, ${ }^{3}$ Mohamed Al Kersh ${ }^{4}$ 'Prof. of Orthopaedic surgery Ain Shams University, Egypt ${ }^{2}$ Lecturer Orthopaedic surgery Ain Shams University, Egypt ${ }^{3}$ Assistant Prof. Orthopaedic Surgery,Ain Shams University, Egypt

${ }^{4}$ Lecturer Orthopaedic surgery Ain Shams University, Egypt
\end{abstract}

Correspondence: Ramy Ahmed Diab, Assistant Prof

Orthopaedic Surgery, Ain Shams University, Egypt, Tel

01005408239,+20-2-2205566 I, Email ramydiab79@gmail.com

Received: May 12,2017 | Published: May 29, 2017

\section{Introduction}

Infected nonunion was defined as a condition characterized by failure of fracture to show progressive evidence of healing and associated with persistence of infection at the fracture site for 6 to 8 months. ${ }^{1,2}$ It commonly occurs following open fractures and fractures caused by high-energy trauma or as a post operative complication after internal fixation. ${ }^{3,4}$ Infected nonunion of the long bones especially the femur is one of the most challenging complication to manage as it is associated with many problems as deformity, limb length discrepancy, joint stiffness, Osteopenia, skin sinuses, resistance to antibiotics, bone and soft tissue defects. ${ }^{5}$ There is considerable social, financial, physical, and psychological impact on the patient. ${ }^{6,7}$

There are many treatment modalities for infected nonunion but none of them is considered the gold standard. ${ }^{8}$ After debridment of infected nonunion, the bone defect is managed by several methods like autogenous cancellous bone graft but it is feasible only in small defects. Another method is segment transfer by the use of external fixators. In which the patient suffers from the long duration of external fixation (EF) which predispose to pin track infection, and adjacent joint stiffness or contracture. An additional problem is the delayed union at the docking site. ${ }^{9}$ Another method to treat large defect is by the use of free vascularized graft but it carries the risk of refracture and nonunion. ${ }^{10}$

In our study, we compared between one stage strategies in which we did irrigation and debridment then definitive fixation with external fixation in the same session versus two stage strategies which include irrigation and debridment in first session then bed rest with no fixation for 6 weeks with use of systemic antibiotic, and follow up with ESR $\&$ CRP till control of infection the second session surgery in the form of internal then we compared between both methods as regard: nearby joint range of motion, time till full union, number of operations and associated complications.

\section{Patients and methods}

We retrospectively reviewed the results of 30 patients operated for infected non-union of femoral shaft fractures; all patients had nonunion with persistence of infection at the fracture site for more than 8 months.

There were 27 males and 3 females with a mean age of 24.76 years (19-34), all patients were subjected to the routine investigations for pre-anesthetic check up and X-rays for the affected limb.

16 patients were operated by a single stage strategy with debridement of the fracture site through lateral approach with thorough excision of all infected tissues and necrotic bone and then fixation with ilizarov or uniplaner external fixation was done with acute shortening and compression at the fracture site in patients with bone defects of $2 \mathrm{~cm}$ or less, and use of autogenous cancellous bone graft was done in patients with bone defects more than $2 \mathrm{~cm}$. (Figure $1(\mathrm{~A}-\mathrm{C}))$
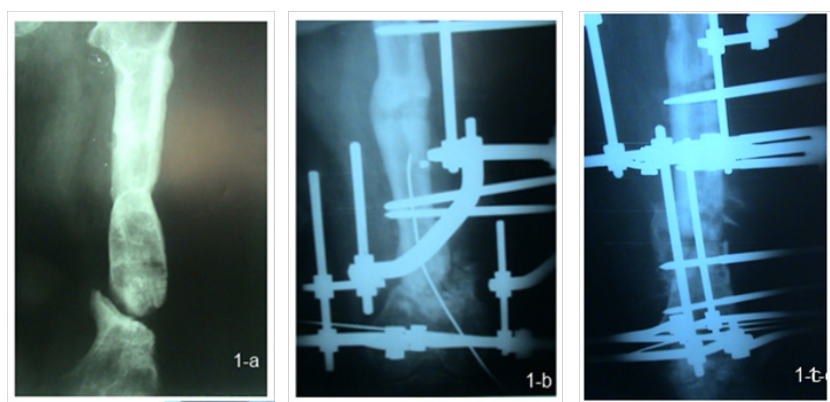

Figure I (A) Femoral infected non union. (B) Postoperative by single stage, and $(\mathrm{C})$ After union.

14 patients were operated by a 2 stage strategy including debridement at the fracture site through lateral approach with excision 
of all infected tissues and necrotic bone with no external fixation in the first session, then rest and parenteral antibiotic was given for 4 to 6 weeks and follow up with serial ESR \& CRP were done before second session, 6 weeks after the first session; the second session was done through fixation by locked intra medullary nail with use of autogenous cancellous bone graft in patients with bone defects more than $2 \mathrm{~cm}$ (Figure 2A) (Figure 2B).
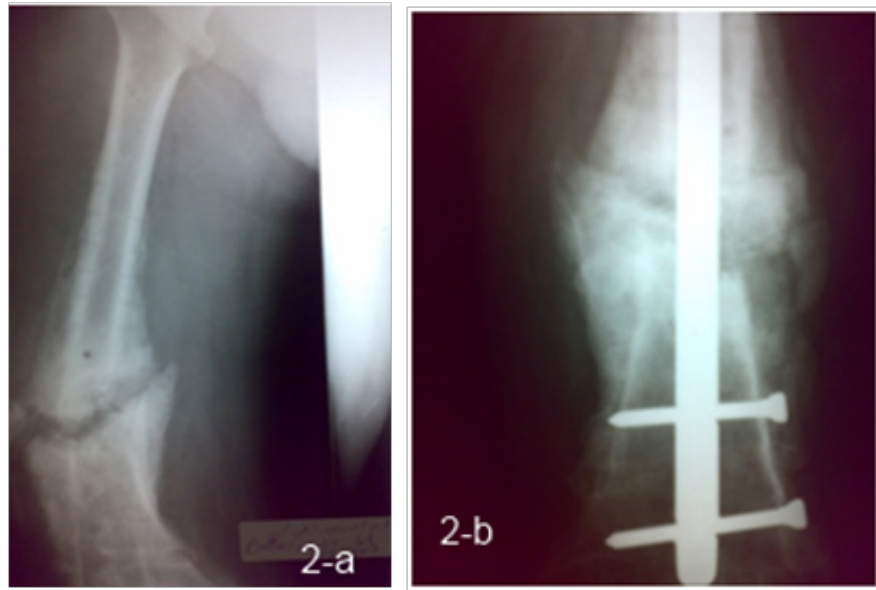

Figure 2 (A) Femoral infected non union after removal of implant in $I^{\text {st }}$ stage. (B) $2^{\text {nd }}$ stage fixation by nail.

Follow up and assessment of the patients were done as regards: cure of infection, duration till union, occurrence of complications such as knee stiffness, pin tract infection, or limb length discrepancy.

Monthly X-rays were done till radiological evidence of full union, early weight bearing and knee range of motion were encouraged.

\section{Results}

All statistical procedures were carried out using SPSS version 15 for Windows (SPSS Inc, Chicago, IL, USA). Continuous variables are expressed as mean and Standard Deviation. Categorical variables are expressed as frequencies and percents. Student $t$ test was used to compare continuous variables .Fisher's exact test was used to examine the relationship between Categorical variables. A significance level of $\mathrm{P}<0.05$ was used in all tests.

There was no significant difference between two study groups as regard age or sex. The mean age for one stage cases was 24.4 years and for two stages cases it was 25.1 years. Males represented $87.5 \%$ of cases in the one stage group compared to $92.9 \%$ of two stage group.

There was no significant difference between two study groups as regard type of nonunion and duration of nonunion.93.8\% of cases with vascular nonunion in the one stage group versus $92 \%$ in the two stage group. Mean duration of nonunion was 26.8 months in the one stage group versus 29.7 months in the two stage group.

There was a highly significant difference between two study groups as regard Duration till union and ROM 6 months after healing; the one stage group showed longer mean duration till union (11.19 months) compared to two stages group(9.36 months). Regarding ROM, two stage group had higher ROM (68.5) compared to one stage (18.75).

There was no significant difference between two study groups as regard occurrence of complication; as $31.3 \%$ of one stage cases had complication compared to $50 \%$ of two stage groups. But the complications were different as there were two cases in the second stage strategy had recurrence of infection and none in the one stage strategy while the risk of knee stiffness was higher in the one stage compared to two stage strategy. There was a highly significant difference between two study groups as unexpected surgery and ROM 6 months after healing; all cases in the one stage group (100\%) had unexpected surgery as 6 cases had quadricepsplasty and bone graft in 10 cases compared to $50 \%$ only of two stage surgery as 3 cases had quadricepsplasty, 3 cases had bone grafting and one case had revision of fixation. Regarding ROM, two stage groups had $57 \%$ of cases had 90 degree compared to none of one stage cases $(0 \%)$.

\section{Discussion}

The goal of treatment for infected nonunion of the femur is to eradicate infection, achieve bone healing, and improve the functional result. The basic principles of treatment included debridement, fracture stabilization, soft tissue reconstruction, and systemic and/or local antibiotic treatment. Stable fixation of the fractures is essential for bone union. The main things to consider for any reconstruction plans are the quality of soft tissue envelope, vascular supply and the presence or absence of infection. There are many available treatments, particularly for large defects but most recently, a two-stage induced membrane technique pioneered by Masquelet and colleagues has received extensive attention. ${ }^{11}$ The principal method of fixation of the femur after debridment is by external fixation but this method of fixation is cumbersome and is associated with a lot of complications as pin track infection and knee extension contracture.

Also, many authors who use the Ilizarov technique have tried to shorten the duration of frame application to avoid the problems associated with its use. ${ }^{12,13}$ The goal was to reduce patient discomfort to the minimum and avoid the complications of long time EF.

In infected nonunion of the long bone, there are two basic strategies of treatment: the "one stage" strategy in which elimination of infection by debridment and stabilization by external fixation was done in one stage, and the "two stage" strategy in which elimination of infection by debridment was done in $1^{\text {st }}$ stage and the fixation by internal fixation was done in another stage after 6 weeks on antibiotics.

To our knowledge, No one before compare between the two strategies, in our studies there are some patients refuse the external fixation in the management of infected nonunion as it is cumbersome to the patients.

In our study, there were two cases suffered from recurrence of infection in the two stage group, three cases suffered from refracture in the one stage group and one case in the two stage group; this was mainly due to higher incidence of knee extension contracture in the one stage group from long period of external fixation with muscle tethering and bad compliance of the patients as regard physiotherapy (Table 1).

Reported external fixation for infected nonunion of the long bones with a good result. ${ }^{14}$ However, there are many problems that may be encountered with external fixation for femoral fractures. Pin-track infection often occurs because of poor drainage of discharge from the femur. It usually takes too long for immobilization because of the risk of refracture or angulations after premature removal of the external fixators. Motion of the thigh is unavoidable with external fixation. Therefore, external fixation of the femur increased the risk for pintrack infection and restriction of motion of the knee by binding down the quadriceps muscle and should be used only in selected cases. 
Table I Comparison of complications of the two groups

\begin{tabular}{lll}
\hline Complications & Single stage strategy & Two stages strategy \\
\hline Pin tract infection & 2 & 0 \\
Refracture & 3 & I \\
$\begin{array}{l}\text { Recurrence of } \\
\text { infection }\end{array}$ & 0 & 2 \\
$\begin{array}{l}\text { Failure of union } \\
\begin{array}{l}\text { Extension } \\
\text { contracture of knee }\end{array}\end{array}$ & 0 & 1 \\
\hline
\end{tabular}

In our study we find that the two stage management of femoral infected non union increase the late knee range of motion, decrease the risk of refracture but had higher incidence of recurrence of infection and non union.

\section{Conclusion}

There are two strategies for management of infected non union One of them without external fixation if there is no large bone defect. The two stage strategy had better ROM of knee $6 \mathrm{M}$ after healing, less risk of refracture after healing but had higher risk of recurrence of infection.

\section{Acknowledgements}

None.

\section{Conflict of interest}

Author declares there is no conflict of interest in publishing the article.

\section{References}

1. Paley D, Catagni MA, Argnani F, et al. Ilizarov treatment of tibial nonunion with bone loss. Clin Orthop Relat Res. 1989;241:146-165.

2. Young S, Lie SA, Hallan G, et al. Risk Factors for Infection after Intramedullary Nail Operations in Low- and Middle-income Countries. World J Surg. 2013;37(2):349-355.
3. Jain AK, Sinha S. Infected nonunion of the long bones. Clin Orthop Relat Res. 2005;431:57-65.

4. Lu WJ, Li B, Qian HB, et al. One-stage management of infected nonunion using granulated cancellous bone autografting after debridement. Zhonghua Yi Xue Za Zhi. 2010;90(23):1609-1611.

5. Beris AE, Dailiana Z, Johnson EO, et al. Vascularized bone grafts for the management of nonunion. Injury Int J Care Injured 375. 2006;p:S41S50.

6. Patzakis MJ, Zalavras CG. Chronic posttraumatic osteomyelitis and infected nonunion of the tibia. $J$ Am Acad Orthop Surg. 2005;13(6):417-427.

7. Romano CL, Romano D, Logoluso N, et al. Bone and joint infections in adults: a comprehensive classification proposal. Eur Orthop Traumatol. 2011;1(6):207-217.

8. Tu YK, Yen CY, Yeh WL, et al. Reconstruction of posttraumatic long bone defect with free vascularized bone graft: good outcome in 48 patients with 6 years' follow-up. Acta Orthop Scand. 2001;72(4):359-364.

9. Paley D. Problems, obstacles, and complications of limb lengthening by Ilizarov technique. Clin Orthop Relat Res. 1990;250:81-104.

10. Sun Y, Zhang C, Jin D, et al. Free vascularized fibular grafting in the treatment of large skeletal defects due to osteomyelitis. Int Orthop. 2010;34(3):425-430.

11. Micev AJ, Kalainov DM, Soneru AP. Masquelet technique for treatment of segmental bone loss in the upper extremity. J Hand Surg. Am. 2015;40(3):593-598.

12. Emara KM. Hemicorticotomy in the management of chronic osteomyelitis of the tibia. Int Orthop. 2002;26(5):310-313.

13. Wu CC, Chen WJ. Tibial lengthening: technique for speedy lengthening by external fixation and secondary internal fixation. J Trauma. 2003;54(6):1159-1165.

14. Ueng WN, Wei FC, Shih CH. Management of femoral diaphyseal infected nonunion with antibiotic beads local therapy, external skeletal fixation and staged bone grafting. J Trauma. 1999;46(1):97-103. 